\title{
FOREIGN DIRECT INVESTMENT AS \\ A CATALYST FOR INDUSTRIAL DEVELOPMENT
}

James R. Markusen

Anthony J. Venables

Working Paper 6241 
NBER WORKING PAPER SERIES

\section{FOREIGN DIRECT INVESTMENT AS \\ A CATALYST FOR INDUSTRIAL DEVELOPMENT}

James R. Markusen

Anthony J. Venables

Working Paper 6241

http://www.nber.org/papers/w6241

\section{NATIONAL BUREAU OF ECONOMIC RESEARCH \\ 1050 Massachusetts Avenue \\ Cambridge, MA 02138 \\ October 1997}

This paper is part of a programme of research supported by the UK ESRC funded Centre for Economic Performance at the LSE and by the British Taiwan Cultural Foundation. Markusen's portion of the work was supported by a grant from the US National Science Foundation to the NBER. This paper is part of NBER's research program in International Trade and Investment. Any opinions expressed are those of the authors and not those of the National Bureau of Economic Research.

(C) 1997 by James R. Markusen and Anthony J. Venables. All rights reserved. Short sections of text, not to exceed two paragraphs, may be quoted without explicit permission provided that full credit, including $(C$ notice, is given to the source. 
Foreign Direct Investment as a Catalyst

for Industrial Development

James R. Markusen and Anthony J. Venables

NBER Working Paper No. 6241

October 1997

International Trade and Investment

\begin{abstract}
How does an FDI project affect local firms in the same industry? Competition in the product and factor markets tends to reduce profits of local firms, but linkage effects to supplier industries may reduce input costs and raise profits. This paper develops an analytical framework to assess these effects. Circumstances in which FDI is complementary to local industry are established, and it is shown how FDI may lead to the establishment of local industrial sectors. These sectors may grow to the point where local production overtakes and forces out FDI plants. Our results are consistent with the experience of a number of industrial sectors in the NICs.
\end{abstract}

James R. Markusen

Department of Economics

University of Colorado

Boulder, CO 80309-0256

and NBER

markusen@spot.colorado.edu
Anthony J. Venables

London School of Economics

Houghton Street

London WC2A 2AE

UNITED KINGDOM

venables@lse.ac.uk 


\section{Introduction}

Over the past two decades, direct investment by multinational firms has grown significantly faster than trade flows, particularly among the world's most developed economies. International economic activity increasingly takes the form of non-arm's-length trade, involving foreign production by multinational firms and intra-firm trade by those same companies. It is now estimated that about $30 \%$ of world trade is intra-firm. ${ }^{1}$ Yet we have a poor understanding of the ways in which direct foreign investment is just a simple substitute for trade, and ways in which it is something quite different. In the 1970s, many host countries governments and some economists viewed multinational investment as detrimental to host-economies' welfare and development, creating monopoly situations that exploited those economies and stifled local competition. The view in the 1990's is considerably different and more optimistic, suggesting that multinationals have important complementarities with local industry, and may stimulate development in host economies.

In the absence of any micro-economic imperfections, a small foreign direct investment (FDI) project will have no effect on host economy welfare, so if a case is to be made for gains or losses it must rest on the possibility that FDI interacts with, or creates, distortions in the host economy. There are many possible sources for such costs or benefits. One is that FDI creates technological externalities -- knowledge spillovers or demonstration effects -- for the local economy. Econometricians searching for such effects have found evidence that the presence of FDI has a positive effect on domestic firms' total

\footnotetext{
${ }^{1}$ For a review of the literature on trade and direct investment, see Markusen (1995). A recent collection of papers with a more macro outlook are found in Froot (editor) (1993). Recent comprehensive treatments include Caves (1996) and Dunning (1993).
} 
factor productivity and on their propensity to export. ${ }^{2}$ Case study evidence arrives at similar conclusions (Hobday (1995), Chung, Mitchell, Bernard Yeung (1994)). ${ }^{3}$

A second possible source of welfare effect is the interaction between multinational activity and fixed distortions in the economy. These distortions include the tax system, labour market imperfections of various sorts, and non-optimally set tariffs. For example, 'tariff- hopping' FDI will be welfare reducing if the import tariff exceeds its optimal level and the FDI causes a reduction in the quantity of imports.

A third set of possibilities arise at the industry level, as FDI changes the structure of imperfectly competitive industries. The arrival of an FDI project will typically change supplies and demands in a number of related industries. FDI creates additional competition, tending to damage local industry, but competition in one sector may be beneficial to firms in other sectors, for example through price reductions and 'forward linkages' to customer firms. FDI may also create demands for local output, and these 'backward linkages' may strengthen supply industries, this in turn feeding (via forward linkages) to other local firms.

The objective of this paper is to provide an analytical framework within which we can assess the effects of these industrial linkages. To do this we develop a model in which there are several imperfectly competitive industries, linked through an input-output structure. We assume that foreign investment can occur in the market for final goods, thus

${ }^{2}$ Studies include: Aitken and Harrison (1994), Aitken, Harrison and Lipsey (1995), Aitken, Hanson and Harrison (1994), Blomstrom (1991), Blomstrom and Kokko (1995), Blomstrom, Kokko and Zejan (1994), Blomstrom, Lipsey and Zejan (1994), Blomstrom and Wolff (1994), Haddad and Harrison (1993), Kokko and Blomstrom (1995). Blomstrom and Kokko (1995) provides a good survey.

${ }^{3}$ Lopez-de-Silanes, Markusen and Rutherford (1994) contains an applied general-equilibrium model of the North American auto industry, focussing in part on the linkages between final production and parts and engine sub-sectors. 
creating backwards linkages to intermediate goods suppliers. ${ }^{4}$

The first question we address is, what is the effect of entry of a multinational firm on the domestic industry? There are two forces at work. One is a competition effect, under which multinationals substitute for domestic final-goods producers. The other is a linkage effect back to intermediate-goods producers, creating complementarities which could benefit domestic final-goods producers. We investigate the determinants of the relative strengths of these effects. There are situations in which there exists an initial equilibrium in which there is zero local production, and in this case multinational entry can push the economy over to an equilibrium with local production in both the intermediate and final-goods industries, with a resulting welfare improvement.

We then move on to endogenise the entry decision of multinational firms. These firms can either produce a variety in a foreign country or, by becoming multinational, start producing in the local economy. As before, the backwards linkages created by multinationals may cause local industry to develop. However, it may now be the case that the expansion of local production -- in both the intermediate and the final goods industry -is so strong as to drive multinational firms out of the economy. Thus, multinationals provide the initial impetus for industrialisation, but the local industry that develops creates sufficiently intense competition to eventually drive the multinationals out of the market.

These results reflect some of the econometric evidence cited above, and bear a close relationship to the case-study findings in Hobday (1995). He finds a large number situations in which initial investments by developed-country multinationals in developing

${ }^{4}$ Rodriguez-Clare studies a similar mechanism in a more aggregate model in which countries specialise in different final goods. Backwards linkages from multinationals can change efficiency and real income levels, but do not have the industrial development effects on which we concentrate in this paper. 
East Asia created backward linkage effects to local suppliers. Interesting examples include computer keyboards, personal computers, sewing machines, athletic shoes, and bicycles in Taiwan. The initial foreign investments created demand for local suppliers and improved their quality, productivity, and product diversity. Hundreds of local firms entered to supply components or assembly services to multinational firms. This growth of component and other intermediate-goods supply and productivity in turn created a subsequent forwardlinkage effect to the final-goods producers, drawing in more multinationals and domestically-owned firms. There then followed a second-round backward-linkage effect and so forth. In some cases (e.g, bicycles, computers), local firms eventually displaced the original multinational entrants. Our model captures this phenomenon, and identifies characteristics of industries and of multinational firms which are conducive to this occurring.

The next section of the paper sets out the analytical framework, and section 3 studies the effects of multinationals operating in the downstream industry. Section 4 endogenises multinationals' entry decision, and investigates the coexistence of multinational and local firms. Section 5 offers some extensions to the basic model, and section 6 concludes.

\section{The model.}

The ingredients we need in the model sound complex. Clearly, we must have an inputoutput structure with the production of both final goods and intermediate goods, and we choose to work with two industries, one downstream, which we shall refer to as the consumer goods industry, and the other upstream, producing intermediate goods. The presence of intermediate goods per se is of little interest, unless it is combined with imperfections in the industries, in which case it can give rise to pecuniary externalities between firms. The second 
ingredient we need then is imperfect competition. We combine this with increasing returns to scale, so that changes in demand (eg due to backward linkages) change profits and hence the number of firms operating in the industry. This change in production may change the price of goods supplied (forward linkages) which may in turn feed-back to the first industry, so creating cumulative causation.

Despite the complexity suggested by a multi-industry model with imperfect competition and increasing returns to scale, it turns out to be possible to build a fairly simple model that captures these features by using standard tricks from the new trade and economic geography literatures. There are two main simplifying assumptions that enable us to do this. First, we divide firms into types (domestic, foreign and multinational) and assume that within each type all firms are symmetrical -- i.e. identical except for the fact that each produces a slightly different variety of product from all other firms. Second, this product differentiation enables us to sidestep the issue of the precise form of oligopolistic interaction between firms -we shall simply assume that each is a monopolist over its own. As an added bonus it also means that we can have intra-industry trade -- in equilibrium there may be both imports coming from foreign firms and exports from local firms and multinationals. ${ }^{5}$

We shall concentrate attention on a single economy, (the domestic economy), and assume that it contains two monopolistically competitive industries, together with a perfectly competitive 'rest of the economy'. The industries are a downstream industry, subscripted $c$ for consumption, and an upstream industry, subscripted $i$ for intermediates. ${ }^{6}$ Intermediates can be supplied only by domestic firms -- they are non-tradeable, and cannot be imported from

${ }^{5}$ For full development of these techniques (although not in the context of multinationals) see Fujita, Krugman and Venables (1997).

${ }^{6}$ This vertical relationship between the industries is quite restrictive, imposing that only one element of the $2 \times 2$ inter-industry transactions part of the input output matrix is positive. 
elsewhere in the world. ${ }^{7}$ Consumer goods can be supplied by three different types of firms: domestic, foreign, and multinationals. This gives four firm types, and notation for the number of firms, price, and quantity of each firm's output are as follows:
Domestic firms in the intermediate good industry:

$$
n_{i}, p_{i}, x_{i}
$$
Domestic firms in the consumer good industry:
$n_{c}, p_{c}, x_{c}$
Foreign firms in the consumer good industry:
$n_{f}, p_{f}, x_{f}$
Multinational firms:
$n_{m}, p_{m}, x_{m}$

All firms except foreign firms produce in the domestic economy.

\section{Demand:}

Each firm produces a distinct variety of product, and all active firms of a particular type are symmetric. Product differentiation is modelled in the Dixit-Stiglitz manner, meaning that all firms face iso-elastic demand curves for their own variety. With this formalisation it is possible to aggregate differentiated products into industry wide quantity and price indices, both of which are constant elasticity of substitution in form. ${ }^{8}$ The price index is particularly useful. Looking first at the intermediate goods industry, we construct a price index for intermediate goods, $q_{i}$, defined over the varieties of products produced by different firms and taking the form,

${ }^{7}$ See an earlier version of this paper, Markusen and Venables (1997) for a more general model in which intermediates are tradeable. Providing they are not perfectly freely traded, it makes no qualitative difference to the results derived here.

${ }^{8}$ The quantity index can, according to context, be interpreted as a utility or production function, and the price index is the dual expenditure or cost function. 


$$
q_{i}=\left[n_{i} p_{i}^{1-\theta}\right]^{1 /(1-\theta)}
$$

The parameter $\theta$ measures the degree of product differentiation in the industry, a low $\theta$ representing a high degree of product differentiation, and the products becoming perfect substitutes as $\theta \rightarrow \infty$. The total volume of intermediate goods demanded in the domestic economy we shall denote by $I$, (and derive later), so the demand for a single variety is: ${ }^{9}$

$$
x_{i}=p_{i}^{-\theta} I q_{i}^{\theta}
$$

Turning to the $c$-good industry, domestic, foreign, and multinational firms all supply the domestic market. We denote the price index in this market $q_{c}$ and express it as,

$$
q_{c}=\left[n_{c} p_{c}^{1-\epsilon}+n_{m} p_{m}^{1-\epsilon}+n_{f} p_{f}^{1-\epsilon}\right]^{1 /(1-\epsilon)}
$$

where $\epsilon$ measures the degree of product differentiation. The demand for consumer goods in aggregate is $C q_{c}^{-\eta}$ where $\eta$ is the elasticity of this demand with respect to the price index, and $C$ is a constant, measuring the position of the domestic demand curve. ${ }^{10}$ The demand functions for a single firm of each type are given below: (the functional form comes from using Shephard's lemma on the price index, (3)).

$$
\begin{aligned}
& x_{c}=p_{c}^{-\epsilon} C q_{c}^{\epsilon-\eta} \\
& x_{f}=p_{f}^{-\epsilon} C q_{c}^{\epsilon-\eta} \\
& x_{m}=p_{m}^{-\epsilon} C q_{c}^{\epsilon-\eta}
\end{aligned}
$$

9 This can be derived by interpreting the price index as an expenditure function, and using Shephard's lemma. Notice that, by (1) and (2) $n_{i} p_{i} x_{i}=q_{i} I$.

10 The model is partial equilibrium, so income effects are ignored. We shall assume that $\epsilon>\eta$. 
We shall assume through sections 2 - 4 of the paper that the only source of demand for firms' output is the domestic market. We broaden this out in section 5 of the paper.

Supply

Supply of each variety of domestically produced intermediate goods takes place to maximise profits,

$$
\pi_{i}=p_{i} x_{i}-b_{i}\left(x_{i}+F_{i}\right)
$$

Each firm uses primary factors, which are the numeraire. $b_{i}$ is an efficiency parameter which also equals the constant marginal production cost and $b_{i} F_{i}$ is each firm's fixed cost. Given the demand curve, (2), firms set price as, ${ }^{11}$

$$
p_{i}(1-1 / \theta)=b_{i}
$$

They break even when their scale of production is sufficient to cover mark-up revenues which, using (6) in (5), occurs when

$$
x_{i}=(\theta-1) F_{i} .
$$

The number of firms in the industry, $n_{i}$, adjusts until this break even level of output is achieved.

Domestic firms in the consumer goods industry have profits

$$
\pi_{c}=p_{c} x_{c}-\left(x_{c}+F_{c}\right) b_{c}\left[1-\mu_{c}+\mu_{c} q_{i}\right]
$$

${ }^{11}$ We assume non-strategic behaviour, so firms' market power comes only from their monopoly in their own variety of product. 
Input requirements arise both from production and from a fixed input requirement $F_{c}$ with efficiency parameter $b_{c .}$. For the $c$-industry fraction $1-\mu_{c}$ of the input requirement is for primary factors and $\mu_{c}$ for intermediate goods, the price of which is given by the $i$ sector price index, $q_{i} . b_{c} \mu_{c}$ is therefore the input - output coefficient -- the input of industry $i$ required per unit total input requirement industry $c$. Profit maximisation gives pricing rule analogous to (6)

$$
p_{c}(1-1 / \epsilon)=b_{c}\left[1-\mu_{c}+\mu_{c} q_{i}\right]
$$

and zero profit condition

$$
x_{c}=(\epsilon-1) F_{c}
$$

Once again, we shall assume that the number of domestic firms, $n_{c}$, is determined by this zero profit condition.

Turning now to multinationals, their profits in this country are

$$
\pi_{m}=p_{m} x_{m}-\left(x_{m}+F_{m}\right) b_{m}\left[1-\mu_{m}+\mu_{m} q_{i}\right]
$$

$b_{m}$ is an efficiency parameter, and the coefficient $b_{m} \mu_{m}$ gives the multinational's requirement of locally produced intermediate goods per unit output. This may differ from domestic firms' input coefficient both because of efficiency differences $\left(b_{m} \neq b_{c}\right)$, and because multinationals may source their intermediates differently. For example, $\mu_{m}<\mu_{c}$ indicates that the multinational is a less intensive user of locally produced intermediates than are domestic firms. Given this technology, multinationals set price

$$
p_{m}(1-1 / \epsilon)=b_{m}\left[1-\mu_{m}+\mu_{m} q_{i}\right]
$$

Foreign firms simply supply the domestic market at constant price $p_{f}$. 
To complete the model two further steps are needed. First, we have seen that the number of domestic firms $n_{i}$ and $n_{c}$ are determined by free entry and exit to give zero profits. What about the number of multinational and foreign firms? In section 4 we shall endogenise the choice of becoming multinational, but for now we shall simply suppose that this number, $n_{m}$, is exogenous. We shall however allow for the possibility that multinational entry to the market may replace imports, and do this by simply assuming replacement coefficient $\delta_{m f}$. Thus, an exogenous change in the number of multinationals, $d n_{m}$, leads to associated change in the number of foreign firms, $d n_{f}=\delta_{m f} d n_{m}$

Finally, we must find the total local demand for intermediates, $I$. This is a derived demand which comes from the input requirements of local and multinational firms in the consumer goods industry, so

$$
I=n_{c} \mu_{c} b_{c}\left[F_{c}+x_{c}\right]+n_{m} \mu_{m} b_{m}\left[F_{m}+x_{m}\right]
$$

To understand the way the model works it is helpful first to assume that there is no multinational production, so that we may focus on the interaction between domestic firms in the upstream and downstream industries. Figure 1 has on the horizontal axis the number of local firms in the $i$-industry, $n_{i}$, and the vertical axis the number in the $c$-industry, $n_{c}{ }^{12}$ There is an exogenously given number of foreign firms, $n_{f}$. The curves on the figures give combinations of numbers of firms at which there are zero profits in each industry. Consider the zero profit locus for the i-industry, $\pi_{\mathrm{i}}=0$. On this curve there are zero profits in the $i$ industry, and to its right there are 'too many' $i$-industry firms operating, so profits are

\footnotetext{
${ }^{12}$ All figures are produced from numerical examples, and parameter values are given in the appendix.
} 
negative, while to the left demand is high enough for entry of further firms to be profitable. The curve goes through the origin, because when $n_{c}=0$ there is no demand for intermediate goods, and hence no production. It is upwards sloping because increasing $n_{c}$ raises demand -the backwards linkage between the industries.

The curve $\pi_{\mathrm{c}}=0$ is the zero profit condition for the $c$-industry, and determines the value of $n_{c}$ given $n_{i}$. Above the curve there are more firms than can profitably operate, and below there is room for entry. This curve has negative value at $n_{i}=0$ because when no intermediates are available the price index $q_{i}$ is infinite, no $c$-good production occurs, and demand is met by foreign firms. Raising $n_{i}$ increases the supply of intermediates, reduces the price index (the forwards linkage) and, at the point where $\pi_{c}=0$ crosses the horizontal axis, causes $c$-industry production to commence.

The configuration illustrated in figure 1 has three equilibria. At the origin there is an equilibrium with coordination failure between industries, and in which final demand for cgoods is met by foreign firms. ${ }^{13}$ Points $\mathrm{U}$ and $\mathrm{E}$ are both equilibria with local production, but we want to argue that the equilibrium at $U$ is unstable. This will be so if entry and exit occurs in response to instantaneous profit levels. Directions of motion are then given by the arrows on the figure, and we see that the equilibria at $\mathrm{O}$ and at $\mathrm{E}$ are both stable, but that $\mathrm{U}$ is unstable; an increase (decrease) in the number of firms in either industry would lead to the equilibrium at $\mathrm{E}$ (or at $\mathrm{U}$ ).

\section{The effect of multinational entry}

What is the effect of entry of multinationals on these schedules, and hence on the

\footnotetext{
${ }^{13}$ If $n_{f}=0$ then the $\pi_{c}=0$ curve would go through the origin, and the equilibrium at the origin would be unstable -- any entry in either industry would overcome the coordination failure.
} 
equilibrium number of domestic firms operating in each industry? Changes in the numbers of multinationals affect the equilibrium in two ways. First, there is the competition effect. An increase in $n_{m}$ reduces the price index $q_{c}$ (equation (3)) this reducing domestic firms' sales and leading to exit of domestic firms to restore sales of remaining firms to their zero profit level. Second, there is a backwards linkage. The multinational may raise demand for intermediates, $I$, (equation (13)) this raising demand for the $i$-industry and expanding its output. We shall examine the effects of these changes on each of the stable equilibria.

\section{1: Multinational firms and the interior equilibrium:}

How is the stable interior equilibrium of figure 1 (point $\mathrm{E}$ ) altered by entry of a multinational firm? The answer is given in figure 2 , in which the solid lines are the initial position, and the dashed lines which intersect at E' are the position of these curves after multinational entry. Decomposing the shifts in the curves into the competition effect and the backwards linkage effect gives the additional lines on the figure. The competition effect shifts the $\pi_{\mathrm{c}}=0$ locus downwards, and also shifts the $\pi_{\mathrm{i}}=0$ locus to the left; the shifts occur because competition reduces $c$-industry sales which both reduces profits (the $\pi_{c}=0$ shift) and also reduces the derived demand for intermediates (hence the $\pi_{\mathrm{i}}=0$ shift). The backwards linkage generated by multinational production creates demand for intermediates, shifting the $\pi_{\mathrm{i}}$ $=0$ locus to the right. Netting out these shifts gives the dashed curves through $\mathrm{E}^{\prime}$.

The shifts in curves that are illustrated in figure 2 are drawn for a central case in which the point $E^{\prime}$ lies vertically below $\mathrm{E}$. The domestic $c$-industry contracts by the full amount of the sales supplied by the multinational, and there is no net effect on the $i$-industry. All that happens is that multinational production replaces domestic firms' production in an exactly offsetting way $-100 \%$ crowding out -- with no net effect on the $i$-industry. 
This case of $100 \%$ crowding out (E' vertically below $E$ ) is a useful central case, and it is worth deriving the conditions under which it occurs. In this case the number of firms in the intermediate industry, $n_{i}$, is constant, and so therefore is the price of intermediates, $q_{i}$, which in turn implies that $c$-industry prices are constant (equation (9)). For the zero profit condition to hold for firms in the $c$-good industry, it must therefore be the case that $q_{c}$ is constant, (equations (4) and (10)), so totally differentiating the definition of $q_{c}$, (equation (3)), we obtain the value of $d n_{c} / d n_{m}$ for which $d q_{c} / d n_{m}=0$. Now using this in the total differential of the expression for intermediate demand (equation (13)), we derive

$$
\frac{d I}{d n_{m}}=p_{m}^{1-\epsilon} C q_{c}^{\epsilon-\eta}\left[\frac{\mu_{m} b_{m}\left(F_{m}+x_{m}\right)}{p_{m} x_{m}-\delta_{f m} p_{f} x_{f}}-\frac{\mu_{c} b_{c}\left(F_{c}+x_{c}\right)}{p_{c} x_{c}}\right]
$$

where endogenous variables are all evaluated at the equilibrium point. If this expression is zero, then E' lies directly below E. The interpretation is clear. Suppose first that multinational entry has no effect on the number of foreign firms supplying the market, $\delta_{m f}=0$. Then the expression is zero if the ratio of intermediate demand created (the numerator of each term in square brackets) to the value of sales (the denominator) must be the same for multinationals as for domestic firms. If $\delta_{m f}>0$, then the generalisation is that the ratio of intermediate demands to the full effect on domestic supply (including displacement of foreign firms) must be the same for multinationals and domestic firms.

When expression (14) is not equal to zero, then the effects can also be seen on figure 2. If the multinational is a less intensive user of local intermediates than are local firms $\left(\mu_{m}<\right.$ $\mu_{c}$ ) then the backwards linkage effect is smaller, so the equilibrium lies to the left of E' (at E' if $\mu_{m}=0$ ). There has been a contraction of $i$-good production, and this amplifies the reduction in domestic $c$-industry production, $n_{c}$. 
Conversely, suppose that the multinational uses local intermediates and also displaces some foreign firms. This reduces the competition effect, and, if there is $100 \%$ displacement, then the denominator of the first term is zero, there is no increase in supply, no competition effect, and equilibrium is at point $E^{\cdots}$. Domestic $c$-industry production expands via the backwards linkage of the multinational on $i$-production, and the forward linkage from this to $c$ - production. The same thing would occur if $100 \%$ of the multinational's output were exported -- the linkage effect in the numerator of (14) would be positive, but the domestic market supply effect in the denominator would be zero.

This illustrates how characteristics of the project determine its effects on local industry. What characteristics of local industry determine the magnitude of the effects? Consider the case when multinational entry has no effect on market supply, so the equilibrium shifts from $\mathrm{E}$ to $\mathrm{E}^{\prime \prime}$. The increase in domestic production in the $c$-industry will be larger the steeper is the $\pi_{\mathrm{c}}=0$ locus, and this gradient depends on imperfect competition in the $i$-industry. If $\theta$ is very large then varieties of intermediate are near perfect substitutes, $i$-industry firms price-cost mark-ups are small, and the $\pi_{c}=0$ locus becomes horizontal. A lower value of $\theta$ means that additional varieties of intermediate product have the effect of reducing $q_{i}$, this giving the forward linkage and positive gradient of $\pi_{\mathrm{c}}=0$. An additional force creating positive gradient in $\pi_{\mathrm{c}}=0$ would arise if we added strategic interaction between firms in the $i$-sector.

Increasing $n_{i}$ would then typically reduce $p_{i}$ (for example, in Cournot competition as each firm's market share shrinks), strengthening the forward linkage effect.

What are the implications of the changes illustrated on figure 2 for host country welfare? We assume a constant supply price of primary factors and that all firms are making zero profits. The only source of welfare gain is therefore consumer surplus coming from increased supply of $c$-industry products, and this is measured by the price index, $q_{c}$. Since this 
is decreasing in $n_{c}$ and increasing in $p_{c}$ (equation (3)), and $p_{c}$ is in turn decreasing in $n_{i}$ (via the forward linkage, equations (9) and (1)), we know that welfare is increasing in both $n_{c}$ and $n_{i}$. Iso-welfare contours are therefore downward sloping on $n_{c}, n_{i}$ space.

The welfare economics of multinational entry can now be established. Adding multinational supply in the $c$-industry reduces $q_{c}$ directly (equation (3)), so shifts the isowelfare contours, giving higher welfare at each point on $n_{c}, n_{i}$ space. If the equilibrium moves from $E$ to $E$ ' there is no change in welfare -- multinationals are a perfect substitute for local firms. If multinationals create smaller backward linkages than domestic firms so the equilibrium is to the left of E', then there is a welfare loss. But if they export their output so the equilibrium moves to $E^{\prime \prime}$ then the effect is to increase welfare. The necessary and sufficient condition for welfare gain is that the expression given in (14) is positive, i.e. the ratio of multinational's demand for intermediates to their impact on domestic supply, should exceed this ratio for domestic firms.

\subsection{Competing imports and cumulative causation:}

Now suppose that the initial equilibrium is at point $O$ on figure 1 . What is the effect of multinational entry on this equilibrium? We can establish this by looking at figure 2 again, but now in the region close to the origin. Consider a process of steady expansion of multinational presence in the economy, shifting the curves from their original position. As the $\pi_{\mathrm{i}}=0$ locus shifts to the right so local $i$-industry production starts up, and the number of firms, $n_{i}$, is given by the intersection of $\pi_{i}=0$ with the horizontal axis. At first these points lie above the $\pi_{c}=0$ locus, so there is still no production by domestic firms in the $c$-industry. What has happened is that demand for intermediates from the multinational has caused intermediate production to start, but the forward linkages this creates are insufficient for local $c$-industry production to 
commence -- particularly since it is facing an adverse competition effect from the multinationals, shifting $\pi_{\mathrm{c}}=0$ downwards.

During this process the point $\mathrm{U}$ in figure 3 is shifting downwards and to the right, and at some point it reaches the horizontal axis. When this point is reached the equilibrium with $n_{i}$ $>0$ and $n_{c}=0$ becomes unstable, and our entry/ exit process flips the equilibrium to the interior stable equilibrium given by the intersection of the loci at $\mathrm{E}^{\prime}$. The forward linkages created by the $i$-industry become strong enough for domestic $c$-industry production to start, but this creates backward linkages, and so on -- cumulative causation comes into operation as the production in the two industries is self-reinforcing. And of course, if multinational production had a less adverse competition effect, then the jump would occur earlier, and the eventual equilibrium would be at a point on $\pi_{c}=0$ to the right of $E^{\prime}$.

What we see in this case then is that multinational entry acts as a kind of catalyst for the development of local industry. Just as described in the case studies refered to in the introduction, it leads to entry of intermediate suppliers which in turn leads to local production. Furthermore, there are unambiguous welfare gains from this process. A discontinuous increase in local production of $c$-industry products is associated with discontinuous fall in the price index $q_{c}$ and gain in welfare.

\section{Endogenous multinationals}

So far, we have taken the entry of multinationals as exogenous. But why can multinationals enter when it is not profitable for national firms to do so? And if many multinationals enter can they coexist with national firms, or will continuing entry by multinationals lead to the destruction of local industry? To answer these questions we must endogenise the entry of multinationals, establishing a decision rule to determine their entry. 
We shall assume that there is a fixed population, $\bar{n}$, of multinational and foreign firms so $n_{m}+n_{f}=\bar{n}$. Each of these firms chooses either to be multinational, establishing local production, or to be 'foreign', importing the same product from a foreign production base. This means that the parameter $\delta_{m f}$ is now equal to unity -- if a firm becomes multinational, then it ceases to be 'foreign'.

Since each of these firms can choose whether to import or invest, the return to establishing local production is,

$$
\Pi_{m} \equiv p_{m} x_{m}-\left(x_{m}+F_{m}\right) b_{m}\left[1-\mu_{m}+\mu_{m} q_{i}\right]-\left(p_{f}-b_{f}\right) x_{f}
$$

The first two terms on the right hand side give the profits earned on multinational production, and the last term is the profits foregone by not supplying the market through imports. We assume that there is a fixed cost $F_{m}$ incurred in establishing local production, but not in supplying the market through imports. The parameter $b_{f}$ is the marginal cost of supplying imports, and includes both production costs and any trade barriers or transport costs. Imports are supplied at price $p_{f}$ which is marked up by factor $\epsilon /(\epsilon-1)$ over marginal cost, $b_{f}$. $n_{m}$ adjusts according to $\Pi_{m}$, and long run equilibrium occurs when $\Pi_{m}=0$.

We now want to combine determination of $n_{m}$ according to this zero profit condition, with the equilibrium conditions of the local industry. Evidently, it may be the case that parameters are such that multinationals can never exist in equilibrium, or can always dominate national firms -- for example, if the cost parameter $b_{m}$, is very high or very low. We shall look only at cases where cost differences between the different types of firms are small enough for coexistence to be feasible.

We can analyse this by looking at zero profit contours for multinationals and for local $c$-industry firms, assuming that the local $i$-industry always adjusts instantaneously to its zero 
profit equilibrium. Figure 3 gives a typical configuration. The axes give $n_{c}$ and $n_{m}$ and the lines are zero profit contours. Looking first at the $\pi_{c}=0$ contour when there are no multinationals, $n_{m}=0$, the points $\mathrm{O}, \mathrm{U}$ and $\mathrm{E}$ correspond exactly to the similarly labelled points on figure 2. At the origin there is no $i$-good production, making $c$-good production unprofitable, so $\pi_{\mathrm{c}}<0$. As we move upwards increasing $n_{c}$, increased $c$-goods supply reduces $q_{c}$ but linkages increase $i$-good production and reduce $q_{i}$. Initially the gains from achieving linkages are larger, raising $\pi_{c}$, until at point $U \pi_{c}=0$. Moving above this raises profits further, but at some point product market competition (falling $q_{c}$ ) outweighs linkages (falling $q_{i}$ ) meaning that profits start to fall, hitting zero at point $\mathrm{E}$.

Moving away from $n_{m}=0$, what happens? Multinational production creates backwards linkages, allowing $c$-industry firms to enter sooner and accounting for the downwards slope of the $\pi_{\mathrm{c}}=0$ locus from $U$. But it also increases final goods supply, accounting for the downwards slope of $\pi_{c}=0$ from $E$. And it is certainly the case that as multinationals' supply gets large enough product market saturation means that no local firms can survive, so for high enough $n_{m}, \pi_{\mathrm{c}}<0$.

The other curve in the figure is the multinationals' entry rule, $\Pi_{m}=0$. The figure is drawn for a relatively low value of $\mu_{m}$, so these firms are less dependent on forward linkages than are local firms. Consequently product market competition forces dominate, meaning that near the origin, where supply is low, $\Pi_{m}>0$, and as we increase supply so we cross the entry line and have $\Pi_{m}<0$.

Given the position of these curves, what are the equilibria? There are three. E and e have production by local firms and multinationals respectively, and $u$ has both types of firms active. But if we follow the entry and exit dynamics as marked by the arrows then two things 
are apparent. First, $\mathrm{u}$ is unstable. ${ }^{14}$ And second, if we start from the origin, there is no dynamic path that leads to point $E$. Our simple dynamics then suggest that $\mathrm{e}$ is the only attainable equilibrium. Multinational firms enter, and at no point during the entry process is entry by a local firm profitable.

Figure 4 is like figure 3 , except that the fixed costs of the local firms, $F_{c}$, are slightly smaller, enlarging the region within which $\pi_{c}>0$ and causing it to intersect with the horizontal axis. As in the preceding figure, there are equilibria at points labelled $\mathrm{E}, \mathrm{u}$ and $\mathrm{e}$, and as before, $\mathrm{u}$ is unstable. However, the dynamic story we now tell is very different. Starting from the origin the dashed line traces out entry of multinationals and, as the $\pi_{c}=0$ frontier is crossed, entry also of domestic $c$-good firms. Entry of these firms creates backwards linkages and increases product supply. Since $\mu_{\mathrm{m}}$ is relatively low, the combination of these effects reduces the profits of multinationals which go negative as the dashed line crosses the $\Pi_{m}=0$ frontier. There is then further entry of local firms and exit of multinationals, leading to long run equilibrium at $\mathrm{E}$.

This story captures some of industry experience we referred to in the introduction. Multinational entry leads, via linkages to and from the $i$-industry, to local production which causes costs to fall fast enough for the local industry to drive multinational firms out of production. Of course, we must remember that there are fixed costs but not sunk costs in this model; in the presence of sunk costs we might expect some multinationals to persist.

We have remarked at several points that the configuration of figures 3 and 4 holds because $\mu_{\mathrm{m}}$ is relatively small. We must now be more precise about this. The equilibrium at $u$ is unstable because as we move along $\pi_{\mathrm{c}}=0$ increasing $n_{m}$ we have

${ }^{14}$ It is saddle point stable, but there is no jump variable to put the system on the stable branch. 


$$
\left.\frac{d \Pi_{m}}{d n_{m}}\right|_{\pi_{c}=0}>0
$$

For what parameter values does this gradient equal zero? We show in the appendix that this gradient is zero at $\Pi_{m}=0$ when the following condition holds:

$$
\frac{\mu_{c} b_{c}\left(F_{c}+x_{c}\right)}{p_{c} x_{c}}-\frac{\mu_{m} b_{m}\left(F_{m}+x_{m}\right)}{p_{m} x_{m}-p x_{f}}=0
$$

(with endogenous variables evaluated at the equilibrium). This is just a variant of the condition derived in section 3.1. The first term gives the ratio of local intermediate demand to sales for a local firm, and the second the equivalent expression for a multinational.

If equation (17) holds then, from the point of view of this model, local production and multinational production are identical -- they have the same backward linkages per unit supplied to the market. What we see is that the iso-profit contours on figures such as 3 and 4 become parallel lines.

Figures 3 and 4 were constructed with the left hand side of (17) positive. What happens if (17) is negative? The configuration is reversed -- like a reversal of the axes -- and an implication of this is that the interior equilibrium remains unstable. Thus there is never a stable equilibrium in which both $n_{m}$ and $n_{c}$ are positive. We can derive this formally by establishing (in the appendix) that the gradient of $\Pi_{m}$ along $\pi_{c}=0$ is

$$
\left.\frac{d \Pi_{m}}{d n_{m}}\right|_{\pi_{c}=0}=K\left[\frac{\mu_{c} b_{c}\left(F_{c}+x_{c}\right)}{p_{c} x_{c}}-\frac{\mu_{m} b_{m}\left(F_{m}+x_{m}\right)}{p_{m} x_{m}-p_{f} x_{f}}\right]^{2} \geq 0
$$

where $\mathrm{K}>0$. The intuitive reason why the term enters with a square is that it measures both 
the backwards linkage from the $c$-industry to the $i$-industry, and the value of the forward linkage from the $i$-industry to the $c$-industry. That is, it measures the change in $q_{i}$ caused by a change in $n_{m}$ (along $\pi_{c}=0$ ) and also the value of the change in $q_{i}$ to multinationals (relative to its value to domestic firms, since we are moving along $\pi_{c}=0$ ).

Our model suggests then that while multinationals can certainly act as a catalyst to stimulate local industry, local industry and multinationals do not coexist. Of course, this result comes from the relatively high degree of similarity between local and multinational firms, and it is easy to imagine circumstances which would permit coexistence. It could occur if firms within each class were heterogeneous (eg differing in efficiency); if the model contained more than one primary factor used by local and multinational firms in different proportions; or if local firms products were viewed, collectively, as differing from multinationals (an Armington assumption).

\section{Export sales and the world market.}

Our analysis of the $c$-good industry has focussed on sales in a single market -- which we have called the domestic market. By restricting sales to the domestic market we have implicitly assumed prohibitive obstacles to exports by local and multinational firms. While this is a great simplification, it is clearly at odds with the experience of many of the most rapidly growing industries in East Asian economies.

Let us now move to a polar opposite case, in which there is perfectly free trade in $c$ goods products. We retain the assumption that intermediate goods are non-tradeable, so supply must equal demand in the domestic market. But since $c$-goods are perfectly tradeable there is a single integrated world market for them, and a single value of the price index. Domestic firms each sell $p_{c} x_{c}$ of sales to this market. The total number of foreign plus 
multinational firms is fixed, ( $\bar{n}$, as before), and if a firm goes multinational then it supplies $p_{m} x_{m}$ of sales from production in the domestic economy, and $p_{f} x_{f}$ less from other production bases. The price index on world market is $q_{c}$, exactly as defined in equation (3).

This is simply a reinterpretation of the model, and analysis is exactly as on figures 3 and 4. The numbers of firms on the axes, $n_{c}$ and $n_{m}$, refer to production in the home economy, but each of these firms now sells on the integrated world market. Competition effects occur on the world market, but linkage effects occur at the national level, because of the assumption that $i$-goods are non-tradeable. In the case illustrated in figure 4 multinational entry leads to the establishment of local industry, as before, and now growth of this industry is associated with both export and domestic sales expansion.

\section{Conclusions:}

The effects of FDI on the home economy may operate through many different channels. This paper provides a simple analysis of just two of these. Product market competition, through which multinationals may substitute for domestic firms, and linkage effects, through which multinationals may be complementary. We have shown how it is then possible for FDI to act as a catalyst, leading to the development of local industry which may in turn become so strong as to reduce both the relative and absolute position of multinationals in the industry. We think that the analysis fits well with some of the case study literature on South East Asian economies referred to in the introduction.

The analysis of this paper suggests many directions for future research. A full general equilibrium setting would allow factor market competition to be added to the picture, and incorporate the effects of industrial growth in driving up real wages. There are also important implications for welfare and policy appraisal of FDI projects. Our analysis points to the need 
to broaden the scope of standard project appraisal techniques to encompass linkages between related activities, and also to address the more difficult possibilities raised by cumulative causation. The research in this paper provides a framework for thinking about these issues, and starts the process of identifying the characteristics of industries and of projects in which FDI is most likely to have a positive impact on host country development.

\section{Appendix}

We can characterise equilibrium by the pricing equations $(6),(7)$, demand curves (4), and the following four equations:

Zero profit by national firms in the c-industry; we choose units for output such that $F_{c}=1 /(\epsilon-1)$ and equilibrium firm scale is unity (see equation 0$)$, so:

$$
1=p_{c}^{-\epsilon} q_{c}^{\epsilon-\eta}
$$

Zero profit for firms in the I-good industry: Setting $F_{i}=1 /(\theta-1)$ and $p_{i}=1,(2)$ and (13) give:

$$
q_{i}^{-\theta}=n_{c} \mu_{c} b_{c}\left[F_{c}+x_{c}\right]+n_{m} \mu_{m} b_{m}\left[F_{m}+x_{m}\right]
$$

and setting $p_{i}=1$

The $c$-goods price index (equation (3))

$$
q_{c}=\left[n_{c} p_{c}^{1-\epsilon}+c_{m} n_{m} p_{m}^{1-\epsilon}+c_{f} n_{f} p_{f}^{1-\epsilon}\right]^{1 /(1-\epsilon)}
$$

The definition of profits for multinational firms: 


$$
\Pi_{m} \equiv p_{m} x_{m}-\left(x_{m}+F_{m}\right) b_{m}\left[1-\mu_{m}+\mu_{m} q_{i}\right]-\left(p_{f}-b_{f}\right) x_{f}
$$

Using (A1), (A2) and (A3) to eliminate $q_{c}$ and $n_{c}$ we can obtain the following relationship between $n_{m}$ and $q_{r}$

$$
\begin{aligned}
p_{c}^{\frac{\eta(1-\epsilon)}{\epsilon-\eta}}-\frac{q_{i}^{-\theta}(\epsilon-1)}{\epsilon \mu_{c} b_{c}}=n_{m}\left(\frac{p_{m}}{p_{c}}\right)^{1-\epsilon}+ \\
\left(\bar{n}-n_{m}\right)\left(\frac{p_{f}}{p_{c}}\right)^{1-\epsilon}-\frac{n_{m} \mu_{m} b_{m}(\epsilon-1)}{\epsilon \mu_{c} b_{c}}\left[F_{m}+\left(\frac{p_{m}}{p_{c}}\right)^{-\epsilon}\right]
\end{aligned}
$$

In this equation $q_{i}$ enters prices $p_{m}$ and $p_{o}$ as well as entering explicitly on the right hand side.

We can rewrite this equation with right hand side in the form,

$$
p_{c}^{\frac{\eta(1-\epsilon)}{\epsilon-\eta}}-\frac{q_{i}^{-\theta}(\epsilon-1)}{\epsilon \mu_{c} b_{c}}=n_{m} A \frac{p_{m} x_{m}-p_{f} x_{f}}{\mu_{c} b_{b}\left(F_{c}+x_{c}\right)}+\bar{n}\left(\frac{\bar{p}}{p_{c}}\right)^{1-\epsilon}
$$

where $A$ is defined as

$$
A=\frac{\mu_{c} b_{c}\left(F_{c}+x_{c}\right)}{p_{c} x_{c}}-\frac{\mu_{m} b_{m}\left(F_{m}+x_{m}\right)}{p_{m} x_{m}-p_{f} x_{f}}
$$

We can now show that $q_{i}$ is increasing in $n_{m}$ if $\mathrm{A}>0$. We shall write,

$$
\frac{d q_{i}}{d n_{m}}=K A
$$

where $\mathrm{K}$ is a positive number, derived from differentiating (A6) with respect to $q_{i}$ 
This establishes the relationship between $n_{m}$ and $q_{i}$, when the domestic industry is in equilibrium. We must now show how this effects $\Pi_{m}$. Using (A1) and (A4) and the demand functions we can derive,

$$
\frac{d \Pi_{m}}{d q_{i}}=A\left(p_{m} x_{m}-p x_{f}\right)
$$

Using this together with (A6) gives equation (18) of the text.

\section{Simulations:}

The figures in the text were derived using the following parameter values.

Figures 1-2:: $\epsilon=\theta=5, \eta=1.1, \mathrm{C}=2, b_{c}=b_{m}=1$.

Figure 1: $\quad \mu_{\mathrm{c}}=0.667, \mu_{\mathrm{c}}=0.667, n_{m}=0, n_{f}=0.15$,

Figure 2: $\quad \mu_{\mathrm{c}}=0.667, \mu_{\mathrm{c}}=0.667, n_{m}=0,0.2, n_{f}=0.15$

Figures $3-4: \because \epsilon=\theta=5, \eta=1.1, \mathrm{C}=10, \bar{n}=10, b_{c}=b_{m}=1, b_{f}=1.4$

Figure 3: $\quad \mu_{\mathrm{c}}=0.333, \mu_{\mathrm{c}}=0.667, F_{c}=0.7, F_{m}=0.37$

Figure 4: $\quad \mu_{\mathrm{c}}=0.667, \mu_{\mathrm{c}}=0.667, F_{c}=0.65, F_{m}=0.37$

\section{References}

Aitken, Brian and Ann Harrison (1994), "Spillover, Foreign Investment, and Export Behavior", NBER Working Paper 4967.

Aitken, Brian, Ann Harrison and Robert E. Lipsey (1995), "Wages and Foreign Ownership: A Comparative Study of Mexico, Venezuela and the United States", 
NBER Working Paper 5102.

Aitken, Brian, Gordon Hanson, and Ann Harrison (1994), "Spillovers, Foreign

Investment, and Export Behavior", NBER working Paper 4967, December.

Blomstrom, Magnus (1991), "Host Country Benefits of Foreign Direct Investment", in

D.G. McFetridge, editor, Foreign Investment, Technology and Economic Growth.

Toronto: University of Toronto Press.

Blomstrom, Magnus, and Ari Kokko (1995), "Multinational Corporations and Spillovers:

A Review of the Evidence", Stockholm School of Economics Working Paper.

Blomstrom, Magnus, Ari Kokko and Mario Zejan (1994), "Host Country Competition and

Technology Transfer by Multinationals", Weltwirtschafliches Archiv 130, 521-533.

Blomstrom, Magnus, Robert E. Lipsey, and Mario Zejan (1994), "What Explains the

Growth of Developing Countries", in W. Baumol, R. Nelson and E. Wolff

(editors), Convergence of Productivity: Cross-National Studies and Historical

Evidence. Oxford: Oxford University Press, 243-259.

Blomstrom, Magnus and Edward Wolff (1994), "Multinational Corporations and

Productivity Convergence in Mexico", in W. Baumol, R. Nelson and E. Wolff

(editors), Convergence of Productivity: Cross-National Studies and Historical

Evidence. Oxford: Oxford University Press, 263-284.

Caves, Richard E. (1996), Multinational Enterprise and Economic Analysis, second edtion.

London: Cambridge University Press.

Chung, Wlibur, Will Mitchell and Bernard Yeung (1994), "Foreign Direct Investment and Host country Productivity: The Case of the american Automotive Components Industry", University of Michigan Working Paper.

Dunning, John H. (1993), The Globalization of Business, London: Routledge.

Fujita, M., P. Krugman and A.J. Venables,.(1997) 'The spatial economy; cities, regions 
and international trade', manuscript.

Haddad, M. and Ann Harrison (1993), "Are There Positive Spillovers from Direct Foreign Investment?", Journal of Development Economics 42, 51-74.

Hobday, Michael (1995), Innovation in East Asia: The Challenge to Japan, Aldershot:

London.

Kokko, Ari and Magnus Blomstrom (1995) "Policies to Encourage Inflows of Technology Through Foreign Multinationals", World Development 23, 459-468.

Lopez-de-Silanes, Florencio, James R. Markusen, and Thomas Rutherford, "Compementarity and Increasing Returns in Imported Intermediate Inputs", Joumal of Development Economics, 45 (1994), 101-119.

Markusen, James R. (1995), "The Boundaries of Multinational Firms and the Theory of International Trade", Journal of Economic Perspectives 9, 169-189.

Markusen, James R. and A J. Venables (1995b), "Multinational Firms and the New Trade Theory", NBER Working Paper 5036.

Markusen, James R. and A J. Venables (1997), 'The impact of foreign direct investment on host economies' processed, LSE.

Rodriguez-Clare, A. (1996), 'Multinationals, linkages, and economic development', American Economic Review, 86, 852-873.

Venables, Anthony J (1996), “Trade policy, cumulative causation and industrial development", Joumal of Development Economics, 49, 179-197. 


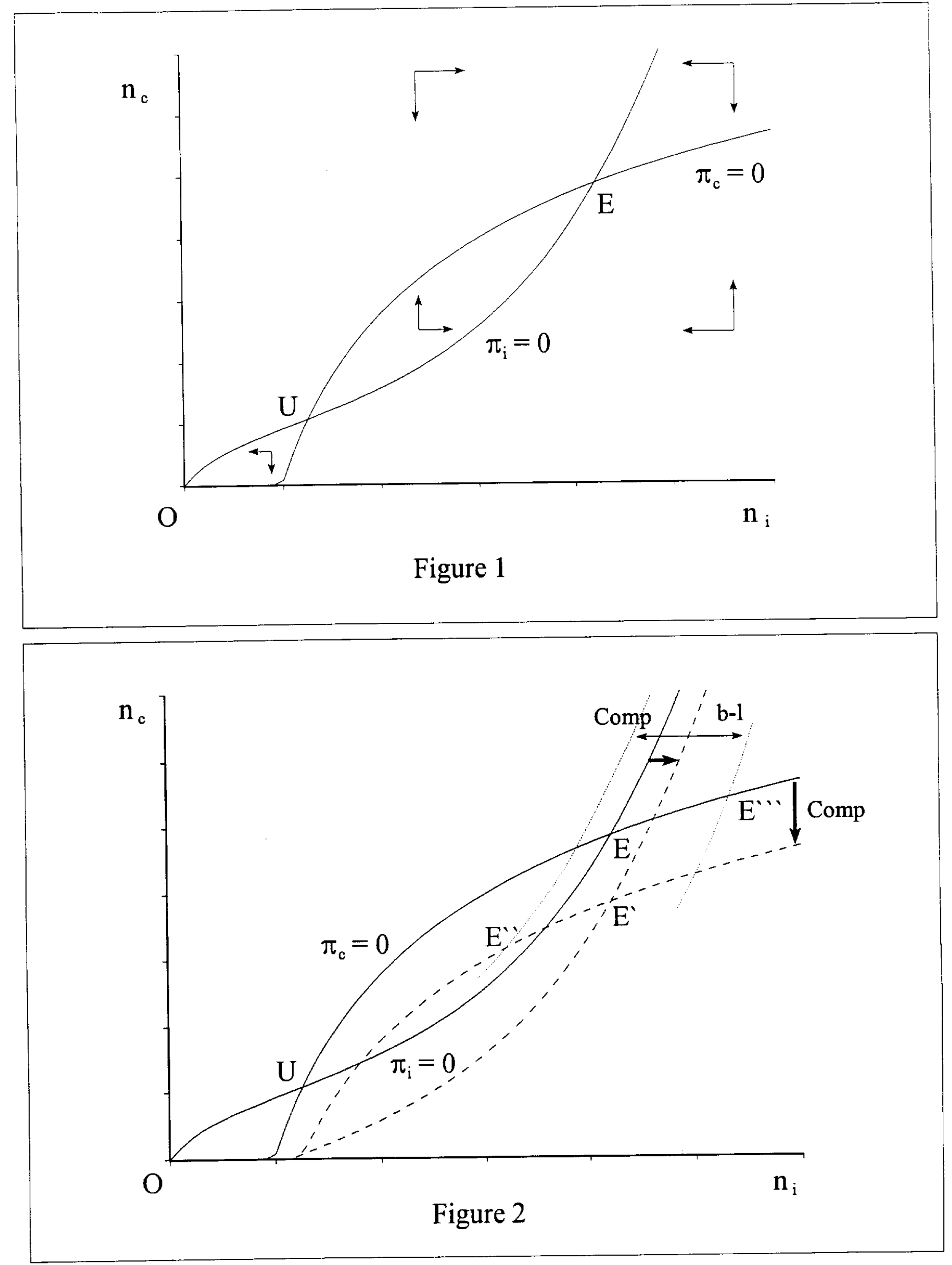




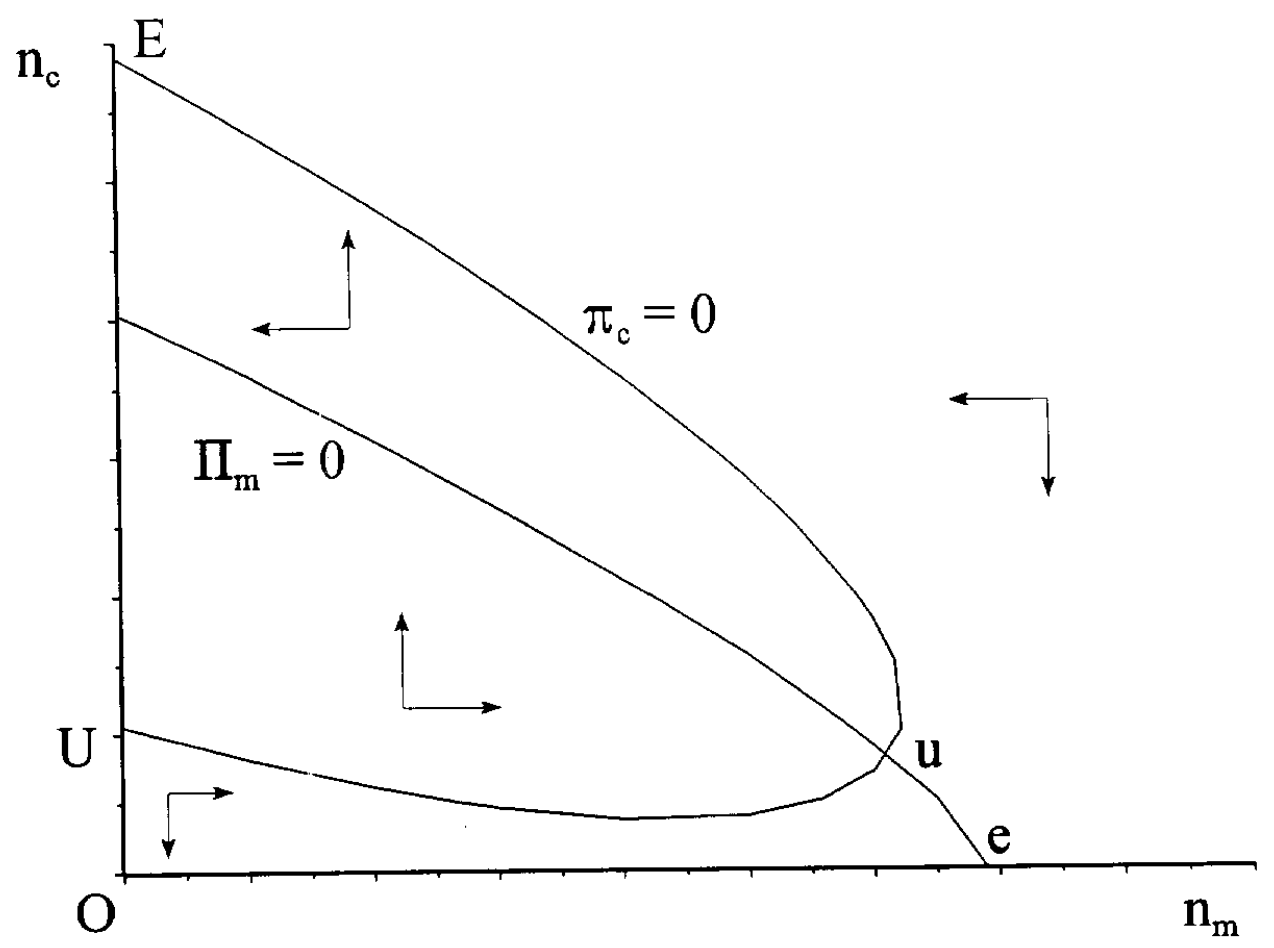

Figure 3:

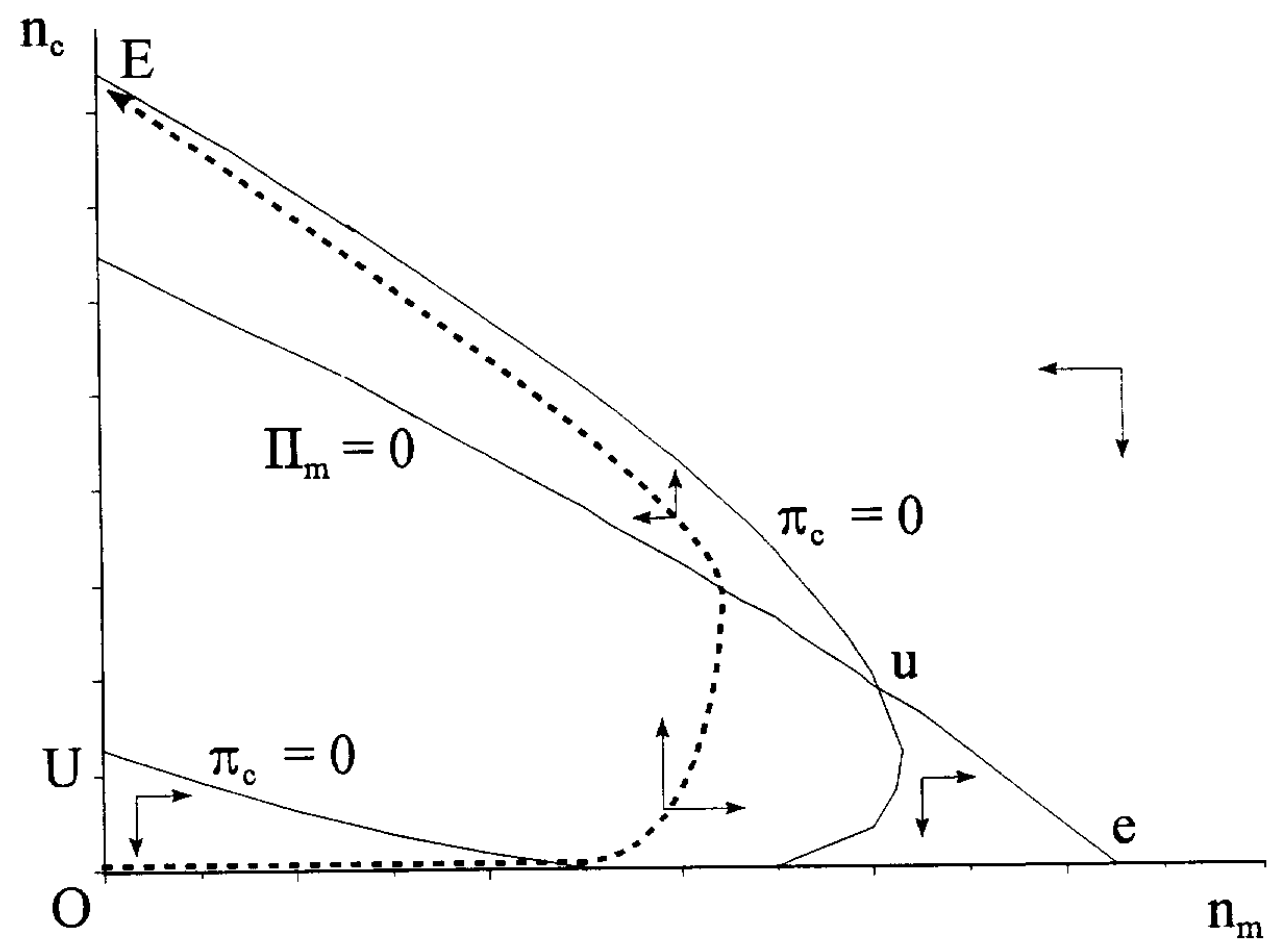

Figure 4: 